\title{
On the Computation of Foldings
}

The process of determining the development (or net) of a polyhedron or of a developable surface is called unfolding and has a unique result, apart from the placement of different components in the plane. The reverse process called folding is much more complex. In the case of polyhedra it leads to a system of algebraic equations. A given development can correspond to several or even to infinitely many incongruent polyhedra. The same holds also for smooth surfaces. In the paper two examples of such foldings are presented.

In both cases the spatial realisations bound solids, for which mathematical models are required. In the first example, the cylinders with curved creases are given. In this case the involved curves can be exactly described. In the second example, even the ruling of the involved developable surface is unknown. Here, the obtained model is only an approximation.

Keywords: folding, curved folding, developable surfaces, revolute surfaces of constant curvature.

\section{UNFOLDING AND FOLDING}

In Descriptive Geometry there are standard procedures available for the construction of the development (net or unfolding) of polyhedra or piecewise linear surfaces, i.e., polyhedral structures. The same holds for developable smooth surfaces. These are surfaces with vanishing Gaussian curvature, composed from cylinders, cones or toruses; the latter are surfaces swept out by the tangent lines of spatial curves.

Of course, the development can also be computed by methods of Analytic Geometry or Differential Geometry. However, the planar counterparts of the spatial parametrized bounding curves need not have a parametrization in terms of elementary functions. An oblique cylinder with a circular basis serves as an example [11].

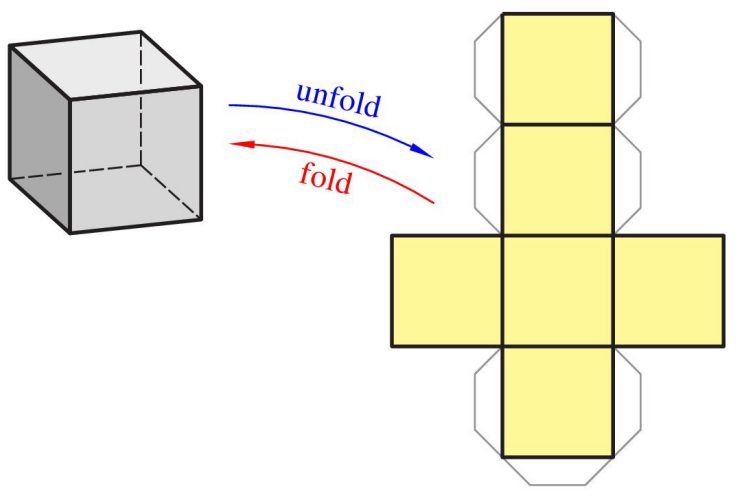

Figure 1. Unfolding and folding

The result of the procedure of unfolding, i.e., the development $\Phi_{0}$ of a given polyhedral or smooth

Received: June 2016, Accepted: November 2016 Correspondence to: Hellmuth Stachel Institute of Discrete Mathematics and Geometry Vienna University of Technology, Wien, Austria E-mail: stachel@dmg.tuwien.ac.at doi:10.5937/fmet1702268S

(C) Faculty of Mechanical Engineering, Belgrade. All rights reserved surface $\Phi$ is unique, apart from the placement of the components in the plane. The unfolding induces an isometry $\Phi \rightarrow \Phi_{0}$ : each curve $c$ on $\Phi$ has the same length as its planar counterpart $c_{0} \subset \Phi_{0}$. Hence, the development shows in the plane the interior metric of the original spatial structure.

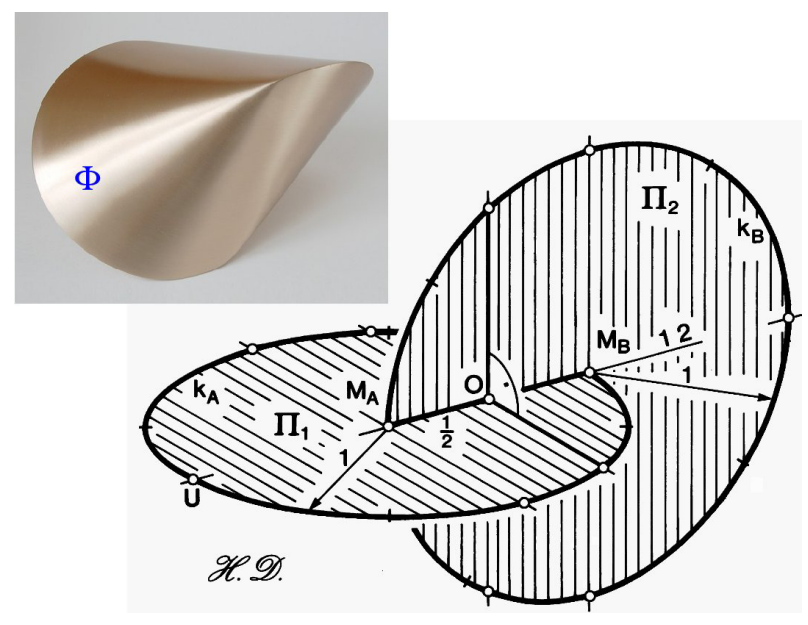

Figure 2. The Oloid is the convex hull of two circles in orthogonal planes such that each circle passes through the center of the other

As an example, in Fig. 2 an Oloid is depicted. This is the convex hull of a particular pair of congruent circles. The Oloid's bounding surface $\Phi$ is of course developable. For its development (see Fig. 3), there is even an explicit arc-length parametrization of the bounding curves available [5, Theorems 2 and 3]. Furthermore, by virtue of the isometry, not only the lengths of curves are preserved during the unfolding, but also the surface area of $\Phi$, which equals that of the unit sphere [5, Theorem 5], provided that the circles defining the Oloid are unit circles.

Remark: The book [4] presents a wide variety of mathema-tical problems around the unfolding and folding of polyhedra. 


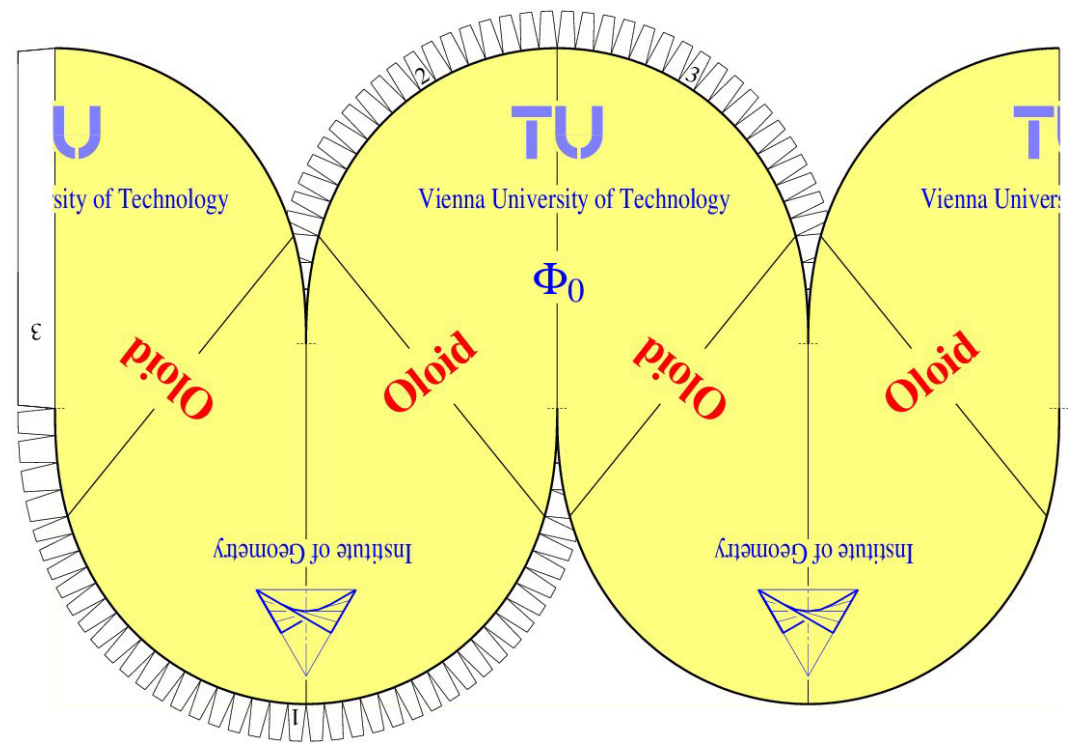

Figure 3. The development of the Oloid's bounding surface

The inverse problem, i.e., the determination of a folded structure from a given development is more complex. In the smooth case we obtain a continuum of bent poses, in general. This is easy to visualize by bending a sheet of paper. In the polyhedral case the computation leads to a system of algebraic equations, and also here the shape of the corresponding spatial object needs not be unique. Sometimes even infinitely many spatial objects with the same development are possible. Then the structure is called flexible. If the system of algebraic equations has an isolated solution with higher multiplicity, one speaks of an infinitely flexible realisation. Otherwise it is called locally rigid (for details see [16], [12] or [13] and the references there).

If a given development allows two realisations sufficiently close together, a physical model can flip from one into the other. Their seeming flexibility results from slight bendings of the faces or clearances at the hinges. A famous example in this respect is a polyhedron called "Vierhorn" (Fig. 4). It is locally rigid, but can flip between its spatial shape and two flat poses in the planes of symmetry. At the science exposition "Phänomena" 1984 in Zürich this polyhedron was exposed and falsely stated that it is flexible (note [18]).

If a polyhedron bounds a convex solid then the result of the folding is unique. We owe this result to the
Russian mathematician Aleksandr Danilovich Alexandrov who stated in his famous Uniqueness Theorem (1941): For any convex intrinsic metric there is a unique convex polyhedron [1]. In this respect, an intrinsic metric is called convex, if for each vertex the sum of intrinsic angles for all adjacent surfaces is smaller than $360^{\circ}$. By the same token, A. I. Bobenko and I. Izmestiev created 2006 an algorithm for the construction of the convex polyhedron with given intrinsic metric [2].

It is of course possible that such a convex metric admits beside the convex realisation still other realisations. Take, e.g., a cube and replace one face by a right pyramid with the bounding square as basis and a sufficiently small height. Then the development remains the same, whether the apex of this pyramid lies in the exterior or interior of the original cube.

The smooth counterpart of Alexandrov's Uniqueness Theorem is the theorem stating the rigidity of ovaloids, which are defined as compact two-dimensional Riemannian spaces of positive Gaussian curvature (see, e.g., $[3,15])$.

In the sequel we present two examples of smooth foldings. In one case the ruling is given; the involved surfaces are cylinders. In the other, much more complex case the ruling of the involved developable surface is unknown.
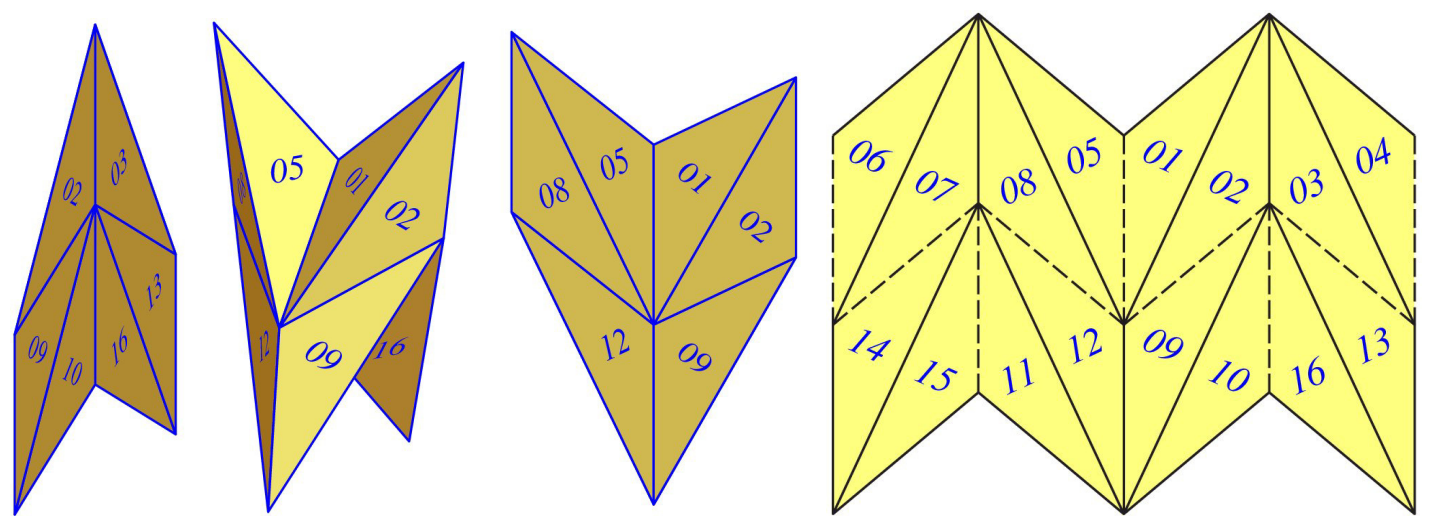

Figure 4. This polyhedron called "Vierhorn" flips between its spatial shape and two flat realizations. Dashes in the development below indicate valley folds. 


\section{FOLDING CYLINDERS WITH A COMMON CURVED} EDGE

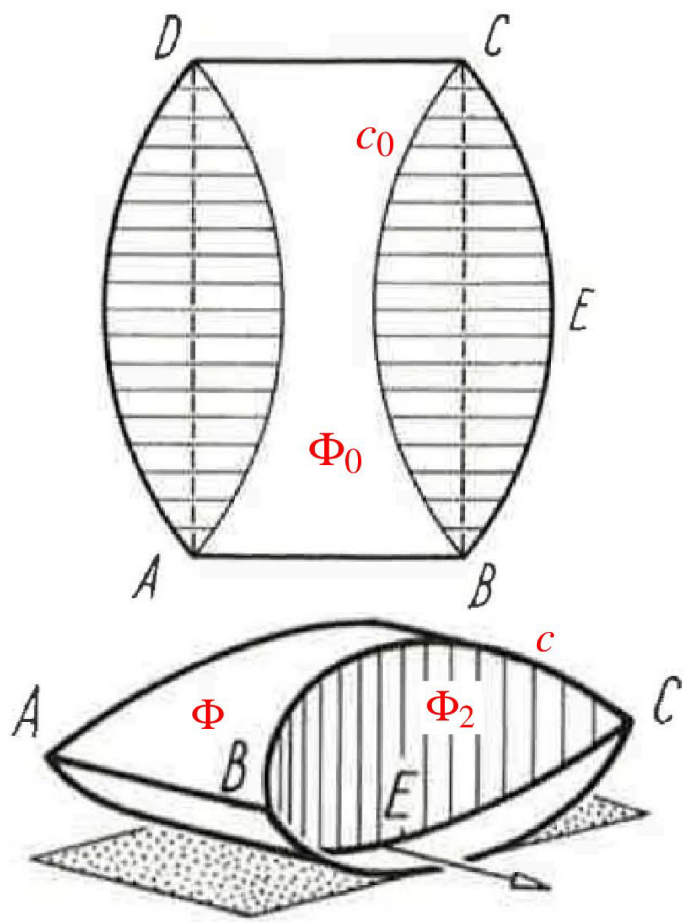

Figure 5. Wunderlich's original figure in [17]: development with crease $c_{0}$ (top) and spatial form (bottom)

A very common way of producing small boxes in shops or in fast-food restaurants is to push up appropriate planar cardbord forms with prepared creases. In the case of creases along circular arcs (see Fig. 5) W. Wunderlich proved in [17] that at the spatial form the creases between the cylinders are again planar. They belong to a family $\mathcal{F}$ of non-elementary curves which are well-known in Differential Geometry since C. F. Gauß: the curves are meridians of surfaces of revolution with constant Gaussian curvature. The family $\mathcal{F}$ includes circular arcs, since spheres have a constant curvature, too. Below, we prove a slight generalization of Wunderlich's result.

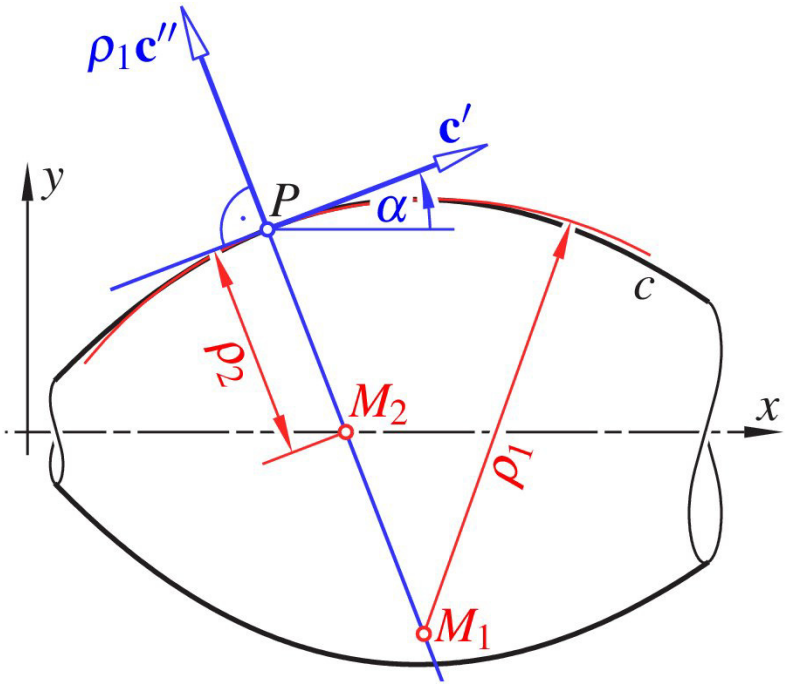

Figure 6. Given a surface of revolution, $\kappa_{1}=1 / \rho_{1}$ and $\kappa_{2}=1 / \rho_{2}$ are the principal curvatures at the point $P \in c$
To begin with, we determine a differential equation which characterizes the curves of $\mathcal{F}$ : Let the meridian $c$ in the $x y$-plane with the twice-differentiable arc-length parametrization

$$
\mathbf{c}(s)=(x(s), y(s)) \text { for } s_{1} \leq s \leq s_{2}
$$

rotate about the $x$-axis (Fig. 6). If primes indicate the differentiation with respect to (w.r.t., in brief) the arclength $s$ then $\mathbf{c}^{\prime}=\left(x^{\prime}, y^{\prime}\right)=(\cos \alpha, \sin \alpha)$ is the unit tangent vector, and $\mathbf{c}^{\prime \prime}=\left(x^{\prime \prime}, y^{\prime \prime}\right)=\kappa_{1}\left(y^{\prime},-x^{\prime}\right)$ is the curvature vector.

At all surfaces of revolution the meridians and parallel circles are the principal curvature lines. Therefore, the signed principal curvatures at the point $P=\mathbf{c}(s)$ are

$$
\kappa_{1}=-\frac{y^{\prime \prime}}{\cos \alpha}, \kappa_{2}=\frac{\cos \alpha}{y} .
$$

The Gaussian curvature $K=\kappa_{1} \cdot \kappa_{2}$ is constant if and only if the arc-length parametrization of the meridian $c$ satisfies the differential equations

$$
y^{\prime \prime}+K y=0, \quad x^{\prime}=\sqrt{1-y^{\prime 2}}
$$

with $K=$ const., provided that $\cos \alpha \neq 0$.

In the case $K=0$ the meridians are lines; the corresponding surfaces of revolution are cones or cylinders. In the remaining cases $K \neq 0$ we obtain the general solutions

$$
\begin{aligned}
& K>0: y=a \cos s \sqrt{K}+b \sin s \sqrt{K} \text { or } \\
& K<0: y=a \cosh s \sqrt{-K}+b \sinh s \sqrt{-K}
\end{aligned}
$$

with constants $a, b \in \mathbb{R}$ and $x=\int \sqrt{1-y^{\prime 2}} d s$.

After specifying an appropriate initial point $s=0$ the arc-length parametrization, there remain - up to similarities - six different cases. This classification dates back to C. F. Gauß (1827) and F. A. Minding (1839) (note [3, p. 169], [6, 277-286], [7], [9, p. 158], or $[15,141-148])$.

In Fig. 7 three of the six types are depicted. Due to Scheffers [11], the curve c with $K=1,0<a<1$ and $b=$ 0 (type 1) shows up at the development of an elliptic cylinder when bounded by a circular section. At type 2 with $K=1$ and $(a, b)=(1,0)$ the meridian c is a half-circle centered on the $\mathrm{x}$-axis. The meridian $\mathrm{c}$ for $K=-1$ and $(a, b)=(1,1)$ of type 3 has the arc-length parametrization

$$
x=\sqrt{1-e^{-2 s}}-\operatorname{arcosh} e^{s}, y=e^{-s}, s>0 .
$$

This defines a tractrix $c$, for which the contacting segment $P T$ at the point $P \in c$ with $T$ on the $x$-axis satisfies $\overline{P M_{1}} \cdot \overline{P M_{2}}=\overline{P T}^{2}=1$.

Theorem. Let $\mathcal{F}_{0}$ be the family of meridians of surfaces of revolution with constant Gaussian curvature $K \neq 0$. Suppose the curve $c_{0} \in \mathcal{F}_{0}$ bounds together with the corresponding axis $a_{0}(=x$-axis $)$ the development $\Phi_{0}$ of a cylindrical patch with generators orthogonal to $a_{0}$. 


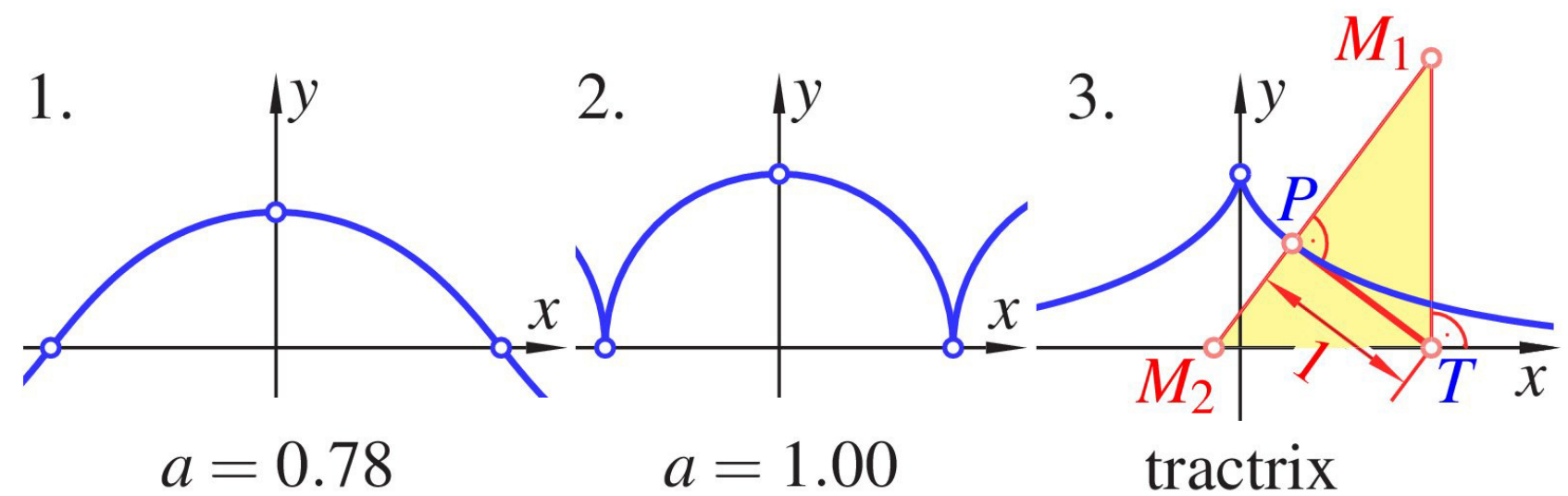

Figure 7. Curves of the family $\mathcal{F}_{0}$ of meridians of surfaces of revolution with constant Gaussian curvature $K \neq 0$

If at a cylindrically bent pose $\Phi$ of $\Phi_{0}$ the corresponding boundary curve $c$ is located in a plane $\varepsilon$ then $c$ is again a member of the family $\mathcal{F}_{0}$ and even with the same curvature $K$. The axis of $c$ is the meet of $\varepsilon$ and the plane of the orthogonal section through the bent counterpart a of the original axis $a_{0}$.
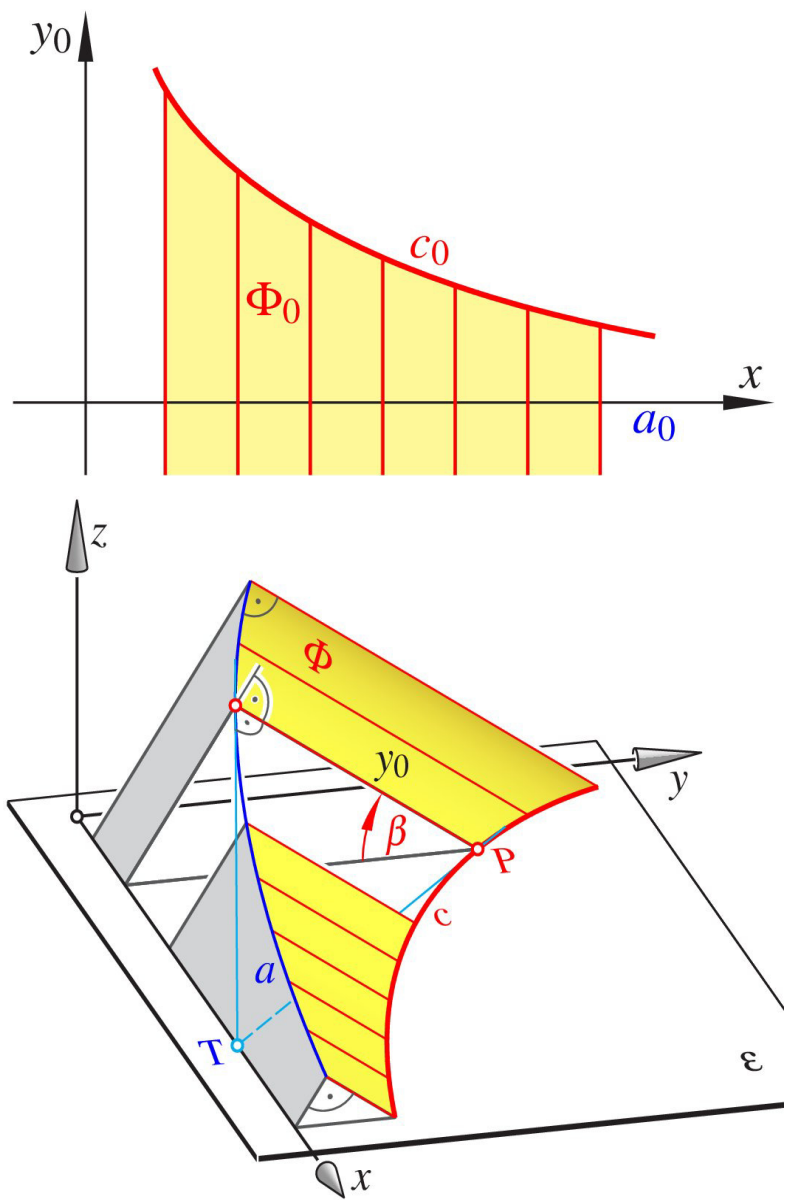

Figure 8. Development $\Phi_{0}$ and bent pose $\Phi$

Proof. The bending from the flat initial pose $\Phi_{0}$ to the cylindrical shape $\Phi$ is an isometry. Therefore the arclength $s$ of $c_{0}$ serves also as arc-length of $c \subset \mathcal{E}$. If at the bent pose $\Phi$ the line of intersection between $\varepsilon$ and the plane of the bent cross section $a$ is used as $x$-axis then the ordinate $y_{0}$ of any point of $c_{0}$ and the $y$-coordinate of the corresponding point of $c$ satisfy

$$
y_{0}(s)=y(s) \cos \beta \text {, with } \beta=\text { const. }
$$

being the angle of inclination of the generators of $\Phi$ w.r.t. the plane $\varepsilon$ (Fig. 8). We have $\beta<\frac{\pi}{2}$ since otherwise $c_{0}$ would be a line.

The ordinate $y_{0}{ }^{(s)}$ of the given boundary curve $c_{0}$ satisfies (1). Consequently, the planar section c of $\Phi$ satisfies the same equation $y^{\prime \prime}+K_{y}=0$. This means in particular that the Gaussian curvature $\mathrm{K}$ of the corresponding surfaces of revolution is preserved.

If we plug (3) into the general solutions $y_{0}=y_{0}{ }^{(s)}$, as listed in (2), the coefficients $a_{0}, b_{0}$ are replaced with

$$
a=\frac{a_{0}}{\cos \beta} \geq a_{0} \text { and } b=\frac{b_{0}}{\cos \beta} \geq b_{0} .
$$

This proves the Theorem.

We can perform a continuous bending from $\Phi_{0}$ to $\Phi$ by varying the angle $\beta$ of inclination in an intervall $0 \leq \beta$ $\leq \beta_{1}$. The condition $\left|y^{\prime}\right| \leq 1$, by (1), implies an upper limit $\beta_{1}$ for $\beta$ : The angle $\beta$ cannot be greater than the angle in the initial flat pose between the generators and the boundary $c_{0}$.

Here are a few examples of the Theorem:

- In Fig. 7, type 2, the curve $c$ is a circular arc. Hence, the cylinder $\Phi$ is elliptic and $c_{0}$ a curve of type 1. This confirms Scheffers' result in [11].

- If $c_{0}$ lies on a tractrix (type 3 ) then $c$ is congruent to another portion of the same tractrix. This follows from (4) for $a=b$, but it can also be concluded from the fact that the distance $\overline{P T}$ along the tangent from the point $P \in c_{0}$ to the intersection $T$ with the $x$-axis (see Fig. 8) remains unchanged during the bending from $\Phi_{0}$ to $\Phi$.

- The statement in the Theorem above includes also Wunderlich's particular case (see Fig. 5) with $c_{0}$ of type 2. However, we still need to prove the planarity of the boundary curve $c$ at the box depicted in Fig. 5, bottom. This can be done as follows:

Proof. Physical models of the box demonstrate that its shape is uniquely defined by its development. We show that there is a solution where the four bounding surfaces are cylinders. 
The spatial counterpart $\mathrm{c}$ of the circular $\operatorname{arc} c_{0}$ in Fig. 5 , top, is common for two cylinders. At each point $\mathrm{P}$ of $c$ the geodesic curvature of $\mathrm{c}$ is the same for both cylinders since it is equal to the curvature of $c_{0}$ in the development at the corresponding point. Therefore at $\mathrm{P}$ the tangent planes to the two cylinders must be symmetric w.r.t. the osculating plane of $\mathrm{c}$ at $\mathrm{P}$.

Also the generators of the two cylinders at $\mathrm{P}$ must be symmetric w.r.t. this osculating plane since in both tangent planes the generators include the same angle with the tangent to $\mathrm{c}$, which is the meet of the two planes. The direction of the generators does not change when $\mathrm{P}$ traverses c. Hence, also the osculating plane as well as the binormal of c cannot change its direction. But then the torsion of $\mathrm{c}$ must be zero, and $\mathrm{c}$ is planar.

Remark: An analytic proof of a slightly generalized theorem can be found in [14, Theorem 3].

When we reflect the second cylinder through $\mathrm{c}$ in the plane of c, we obtain an extension of first cylinder beyond its original boundary c. (In rigid origami this is called reflection operation (see, e.g., [10, p. 187]). For each pair of generators, which meet on $\mathrm{c}$, the plane of $\mathrm{c}$ is an exterior angle-bisecting plane.

\section{FOLDING WITH UNKNOWN RULINGS}

Figure 9 shows a development $\Phi_{0}$ with a boundary $c_{0}$, which is a $C^{1}$-curve composed from two straight line segments and two semicircles of equal lengths. Let $A_{0}$ and $C_{0}$ be two opposite points of transition between semicircles and straight line segments for bisecting the boundary. Now the spatial form $\Phi$ is obtained by gluing together, from $A_{0}$ on, the semicircle of one part with the straight segment of the other, and vice versa (Fig. 10 , top to bottom). The question is, how to obtain a mathematical model of the resulting body?

In contrast to Example 1, the crucial point is now that the ruling is unknown, and local conditions are not sufficient for modelling the bent shape. The constraint is of global nature: the boundary $c_{0}$ of $\Phi_{0}$ must finally give a two-fold covered closed curve $c$.
In [8] a general and effective appoximating method is presented in order to compute the spatial form from given planar shapes. Our approach in this particular case is different. The inspection of a physical model (Fig. 10) reveals:

- The corresponding spatial body with the boundary $\Phi$ is convex and uniquely defined.

- The helix-like curve $c$ is a proper edge of $\Phi$; the resulting solid is the convex hull of $c$.

- The spatial body has an axis $a$ of symmetry which connects the spatial position $M$ of the center $M_{0}$ with the remaining transition point $B=D$ on $c$.

- The semicircular disks are bent to cones with apices $A$ and $C$. Hence, the boundary $\Phi$ is a $C^{1}$ composition of two cones and a torse between.

We traverse $c$ from $A$ to $C$ and subdivide it at the transition point $B=D$ into the two parts $c_{1}$ and $c_{2}$. Due to the observations at the physical model, we can state:

(a) The rotation about the axis $a$ of symmetry through $180^{\circ}$ maps $\Phi$ onto itself and interchanges $c_{1}$ and $c_{2}$. Hence, $a$ is orthogonal to the tangent $t_{B}$ at the transition point $B$. The apices $A$ and $C$ are symmetric w.r.t. $a$. The generator $g_{M}$ of $\Phi$ through the central point $M$ is cylindric and has a tangent plane orthogonal to $a$.

(b) Because of the straight segments of the development $c_{0}$, the developable surface on the left hand side of $c_{1}$ belongs to the rectifying torse of $c_{1}$. With respect to the right hand side, $c_{1}$ is a geodesic circle of $\Phi$.

(c) Since at $A_{0}$ the semicircle is tangent to the adjacent straight segment, the surface $\Phi$ has cone singularities with the intrinsic curvature $\pi$ at the points $A$ and $C$. Therefore, at point $A$ the surface can be approximated by a right cone with the apex angle $60^{\circ}$. The initial tangent $t_{A}$ to $c_{1}$ is a generator of this cone. Consequently, the osculating plane of $c_{1}$ at $A$ coincides with the cone's tangent plane along $t_{A}$, and the rectifying plane at $A$ passes through the cone's axis.

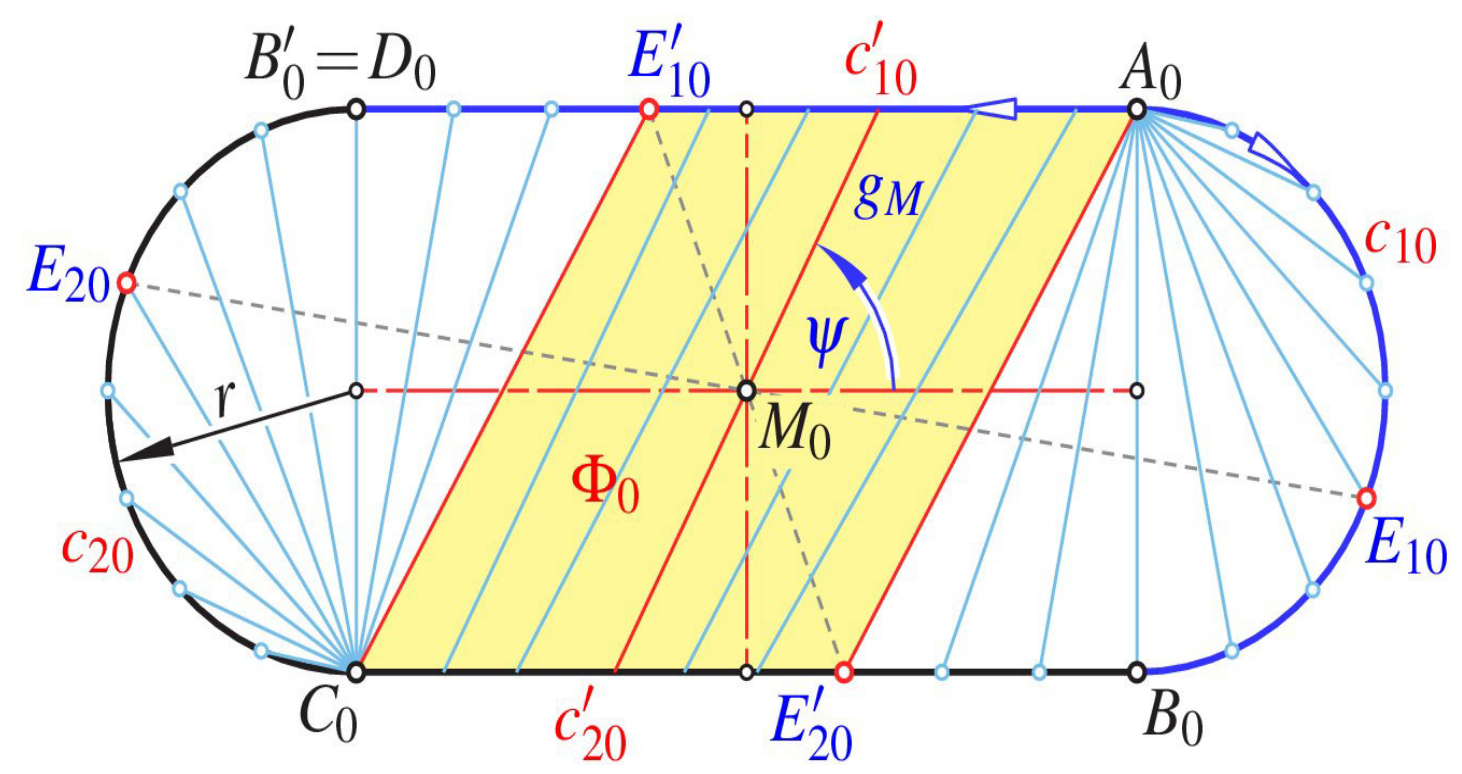

Figure 9. Development of the second example 
(d) $\Phi$ belongs to the connecting torse of $c_{1}$ and $c_{2}$. If $g$ is a generator of $\Phi$ whose counterpart in the development meets both straight segments of the boundary $c_{0}$ then $g$ meets $c_{1}$ and $c_{2}$ at points with parallel and equally oriented tangent vectors.

(e) At the point $E_{2} \in c_{2}$ of transition between the cone with apex $A$ and the continuing torse (see Fig. 9) the tangent to $c_{2}$ must be parallel to the initial tangent $t_{A}$ to $c_{1}$ at $A$. The symmetric point $E_{1} \in c_{1}$ has a tangent parallel to the final tangent $t_{c}$ of $c_{2}$. By virtue of item (d), the tangent indicatrices of the subarcs $A E_{1}$ of $c_{1}$ and $E_{2} C$ of $c_{2}$ must coincide.

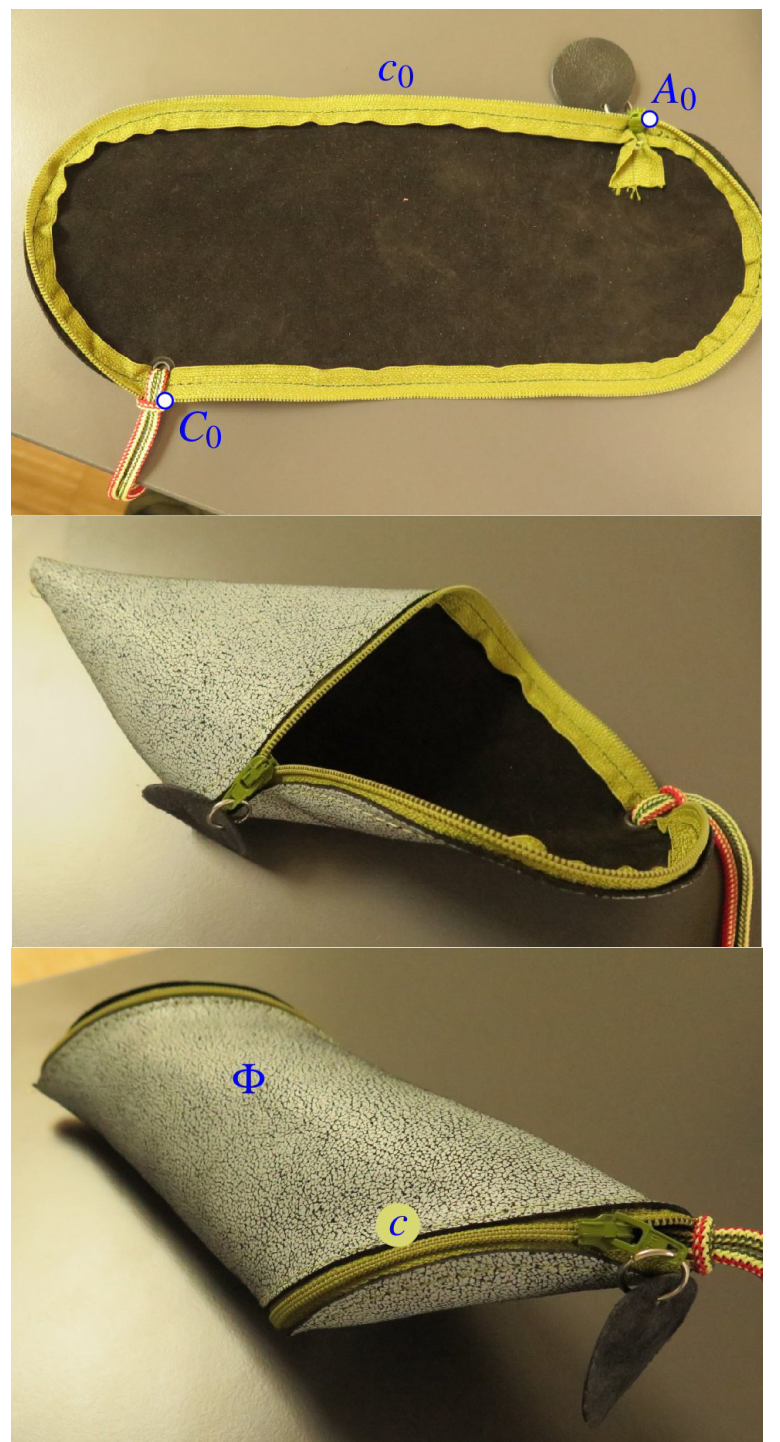

Figure 10. The transition from the development to the spatial form (photos: G. Glaeser)

It turned out that a good approximation arises when we specify the conciding subarcs of the tangent indicatrices as a circular arc. Then the corresponding space curves $A E_{1} \subset c_{1}$ and $E_{2} C \subset c_{2}$ are of constant slope, and their common rectifying torse is a cylinder.

Conversely, if the middle part of $\Phi$ is supposed as a cylinder the arcs $A E_{1}$ and $E_{2} C$, being geodesics, are curves of constant slope w.r.t. generators $g$ of this cylinder. In the development (Fig. 9) all generators $g_{0}$, which meet the two straight segments of $c_{0}$, are of equal lengths. There is a translation along $g$ which maps the arc $A E_{1} \subset c_{1}$ onto the arc $E_{2} C \subset c_{2}$. The half-rotation about the axis $a$ of symmetry maps $E_{2} C$ back to $E_{1} A$. Hence, there must be a half-rotation with an axis $a_{1}$ parallel to $a$ which exchanges $A$ with $E_{1}$ while the arc $A E_{1}$ is mapped onto itself.
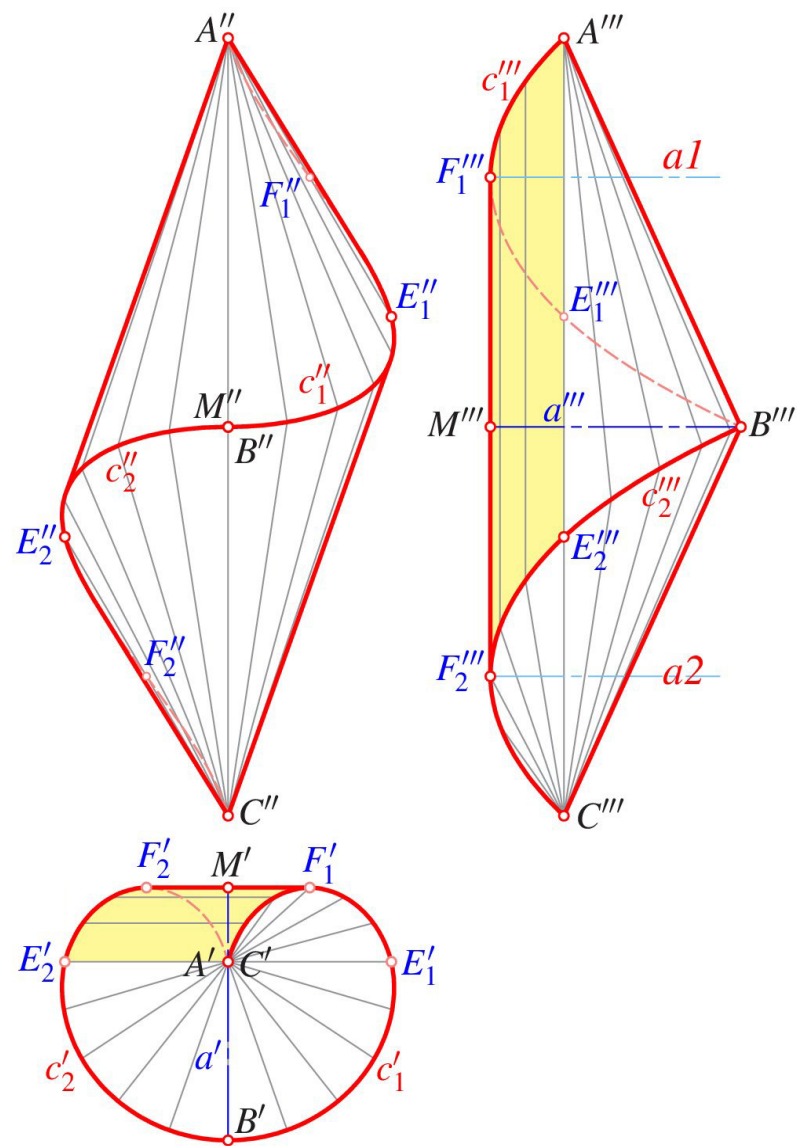

Figure 11. Principal views of the approximation; the cylindrical patch is shaded

This means, the slope curve $A E_{1}$ has an axis $a_{1}$ of symmetry which meets $c_{1}$ at a point $F_{1}$. The axis $a_{1}$ must be orthogonal to the tangent plane of the cylinder at $F_{1}$ in order to guarantee that the complete arc $A E_{1}$ is a smooth slope curve. Since $E_{1}$ and $C$ are the images of $A$ under reflections in parallel axes $a_{1}$ and $a$, respectively, the points $A, C, E_{1}$, and $E_{2}$ lie in a plane orthogonal to $a$ (note the side view in Fig. 11).

The approximation depicted in Figs. 11 and 12 yields the following numerical results: The slope angle of $c$ w.r.t. the cylinder is approximately $\psi=54.53^{\circ}$. The 'width' $\overline{M B}$ of the solid, in terms of the semicircles' radius $r$, is $1.18 r$, the 'height' $\overline{A C}=3.635 r$, and the angle $A B C=130.67^{\circ}$.

These data correspond quite well to the physical model. However, in [14] it is noted that there is still a tiny contradiction inherent in the model with the cylindrical patch. So, at the exact model, the torsal part between the two cones of $\Phi$ must deviate slightly from a cylinder.

We can fold the sheet shown in Fig. 9 in two ways, since we can choose the depicted side either in the interior of the solid or in the exterior. At the first choice 
the curve $c$ has negative torsion (see photos in Fig. 10). Otherwise its torsion is positive (see Fig. 12).

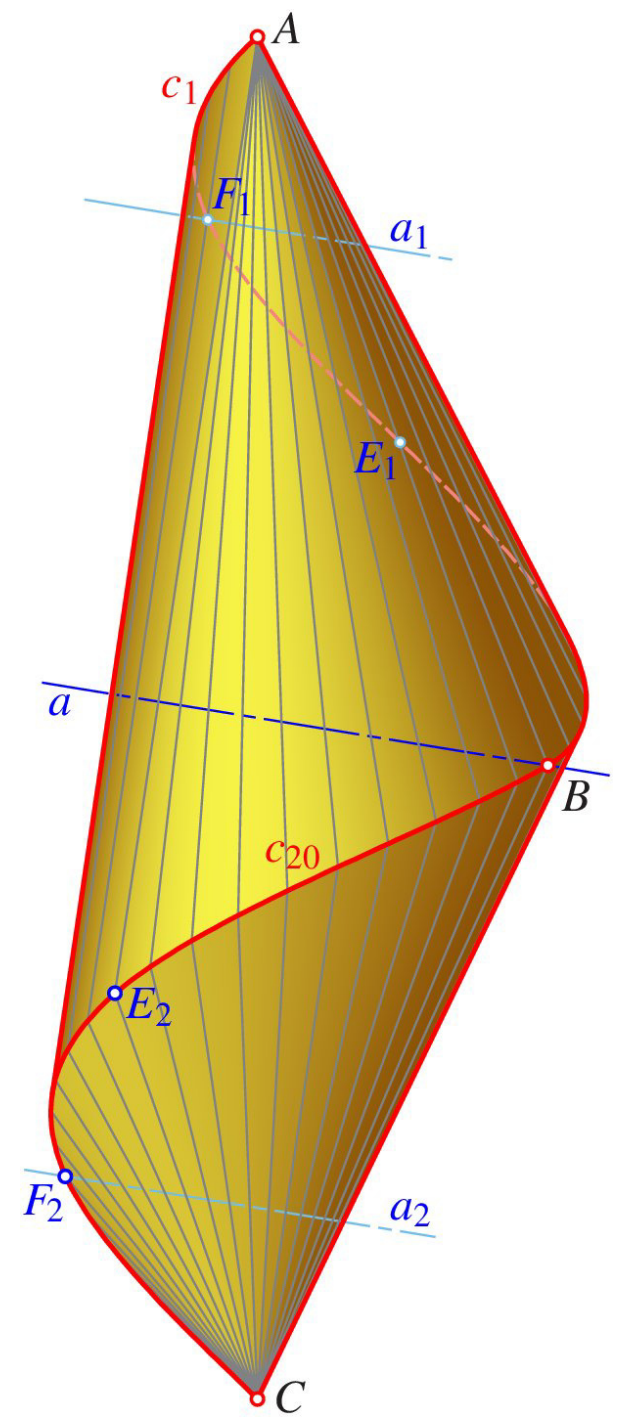

Figure 12. Approximation with a cylindrical patch

\section{REFERENCES}

[1] Alexandrov, A. D.: Convex Polyhedra, Springer Monographs in Mathematics, Springer 2005 (first Russian ed. 1950).

[2] Bobenko, A. I. and Izmestiev, I.: Alexandrov's theorem, weighted Delaunay triangulations, and mixed volumes. Annales de l'Institut Fourier, Vol. 58, No. 2, pp. 447-505, 2008.

[3] do Carmo, M. P.: Differential Geometry of Curves and Surfaces. Prentice-Hall Inc., Englewood Cliffs 1976.

[4] Demaine, E. D. and O'Rourke, J.: Geometric folding algorithms: linkages, origami, polyhedra. Cambridge University Press 2007.

[5] Dirnböck, H. et al.: The Development of the Oloid. J. Geom. Graphics, Vol. 1, pp. 105-118, 1997.

[6] Eisenhart, L. P.: An introduction to Differential Geometry, Princeton University Press 1947.

[7] Göttingen Collection of Mathematical Models and Instruments, http://modellsammlung.uni-goettingen .de.
[8] Kilian, M., Flöry, S., Chen, Z., Mitra, N. J., Sheffer, A., and Pottmann, H.: Curved Folding. ACM Trans. Graphics, Vol. 27, No. 3, 2008, Proceedings. SIGGRAPH 2008.

[9] Kreyszig, E.: Introduction to Differential Geometry and Riemannian Geometry. University of Toronto Press 1967.

[10] Mitani, J.: Column-shaped Origami Design Based on Mirror Reflections. J. Geom. Graphics, Vol. 16, No. 2, pp. 185-194, 2012.

[11]Scheffers, G.: Zusammenhang zwischen der Abwickelung eines Kreiscylinders und den Rotationsflächen konstanter Krümmung. Arch. Math. Phys, III. Reihe, Vol. 6, pp. 249-250, 1903.

[12] Stachel, H.: What lies between the flexibility and rigidity of structures. Serbian Architectural Journal, Vol. 3, No. 2, pp. 102-115, 2011.

[13] Stachel, H.: On the Rigidity of Polygonal Meshes. South Bohemia Mathematical Letters, Vol. 19, No. 1, pp. 6-17, 2011.

[14] Stachel, H.: Two examples of curved foldings. Proceedings 17th International Conference on Geometry and Graphics, Beijing 2016, paper No. 48.

[15] Strubecker, K.: Differentialgeometrie III. Theorie der Flächenkrümmung. Sammlung Göschen 1180/1180a, Walter de Gruyter \& Co., Berlin 1959.

[16] Whiteley, W.: Rigidity and scene analysis. In Goodman, J. E., and O'Rourke, J. (eds.): Handbook of Discrete and Computational Geometry, CRC Press, Boca Raton, New York, 1997.

[17] Wunderlich, W.: Aufgabe 300, El. Math., Vol 22, p. 89, 1957; author's solution: El. Math., Vol. 23, p. 113-115, 1958.

[18] Wunderlich, W., and Schwabe, C.: Eine Familie von geschlossenen gleichflächigen Polyedern, die fast beweglich sind. Elem. Math., Vol 41, pp. 8898, 1986.

\section{О ПРОРАЧУНУ САВИЈАҢА КОД ПОЛИЕДАРСКИХ СТРУКТУРА}

\section{Х. Штахел}

Поступак одређивања развијања полиедра у мрежу или развојне површине се назива развијање и даје јединствени резултат, поред постављања различитих компонената у раван. Обрнути поступак који се назива савијање много је сложенији. У случају полиедара оно доводи до система алгебарских једначина.

Дато развијање може да одговара неколицини или бесконачном броју разноликих полиедара. Исто важи и за глатке површине. У раду су дата два примера таквих савијања. У оба случаја просторна реализација је везана за тела за која су потребни 
математички модели. У првом примеру су приказани цилиндри са кривим наборима. У таквом случају кривине се могу тачно описати. У другом примеру чак је и понашање обухваћене развојне површине непознато. Добијени модел овде представља само апроксимацију. 